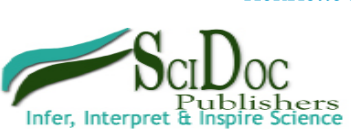

International Journal of Behavioral Research \& Psychology (IJBRP)

ISSN 2332-3000

\title{
Clinical Reasoning and Authentic Clinical Care : The Role of Counter transference
}

Editorial

Henriette Löffler-Stastka, Parth K

Medical University Vienna, Dept. for Psychoanalysis and Psychotherapy, Vienna, Austria.

\section{*Corresponding Author:}

Henriette Löffler-Stastka,

Medical University Vienna, Dept. for Psychoanalysis and Psychotherapy,

Vienna, Austria.

Tel: +43-1-40400-3070

E-mail: henriette.loeffler-stastka@meduniwien.ac.at

Received: November 13, 2013

Published: December 9, 2013

Citation: Henriette Löffler-Stastka, Karoline Parth (2013) Clinical Reasoning and Authentic Clinical Care : The Role of Counter transference. Int J Behav Res Psychol. 1(1e), 1-3.

doi: http:/ / dx.doi.org/10.19070/2332-3000-130001e

Copyright: Henriette Löffler-Stastka (C) 2013. This is an open-access article distributed under the terms of the Creative Commons Attribution License, which permits unrestricted use, distribution and reproduction in any medium, provided the original author and source are credited.

In the mental health sector it is the biggest and most important task of the psychiatrist, psychotherapist or interviewer to make a diagnosis that most closely approximates the inner condition of the patient in order to induce proper therapeutic and psychiatric treatment. In the field of mental illness however, this is often very challenging due to the fact that there are feelings, dynamics and experiences that are central to the mental condition of the patient but cannot be verbally communicated. Especially in the field of trauma, these issues become visible since traumatizing experiences often cannot be remembered. There are varying paths to diagnosis and treatment in the mental health sector differing in method and setting, however they all consist of some sort of assessment in the context of an interaction between mental health professional and patient. We argue that in order to achieve a proper diagnosis and treatment for psychic illness, the interaction between patient and therapist has to be taken into account to facilitate an understanding of internal dynamics. It is our position that only with proper use of countertransference concepts and the understanding of processes of projective identification full use of the therapeutic setting for treatment and diagnosis can be achieved.

In mental health care, we face the question how to offer adequate care for psychic problems in terms of diagnosis and treatment if there are numerous problems that lie so deep they cannot be adequately communicated by the patient. In the case of very early traumata and severe developmentally impairing experiences, the impact on development and psychic functioning in adulthood is significant, however the person affected often only vaguely or not at all remembers them. It must be expected that psychic impairments of that kind lead to extensive problems but there often is no conscious connection between these issues in adulthood and their cause in early childhood.
We suggest that it is of utmost significance for the understanding of a patient's psychic problems and in consequence for diagnosis as well as treatment, that the therapist takes into account not only the feelings voiced and expressed by the patient directly but also those feelings thoughts triggered in the therapist by the patient. These countertransference feelings, we argue, are key in understanding those dynamics, feelings and processes in the patient, which he himself is not aware of. It is our position that, without including these concepts developed in psychoanalytic research, countertransference cannot be used adequately and to its full extent. Countertransference has become a central aspect of thinking about the relationship between patient and analyst and has become a vital tool for treatment in all schools of psychoanalytic thinking (Dresser 1985; Kernberg 1993). Moreover, it has been adopted by many other forms of psychotherapy, which equally make use of it as a central instrument for their work, rendering it ubiquitous and indispensable for modern psychotherapy (Weitzman 1967).

Similarly to transference, countertransference was originally considered to be an obstacle to the analysis by Freud and his colleagues, the widespread belief being that it is an expression of the analyst's unresolved transference to the patient. It was understood as evidence for lacking emotional maturity and competence of the analyst, disturbing and distorting his or her objective position. A significant revision of this concept came with Heimann's paper "On Countertransference" (1950), when psychoanalysts came to regard this phenomenon as the ubiquitous emotional response of the analyst to his patients, which reflect feelings, defences, internal objects and object relationships unconsciously communicated by the patient. She writes: "our basic assumption is that the analyst's unconscious understands that of his patient. This rapport on the deep level comes to the surface in the form of feelings, which the analyst notices in response to his patient, in his 'counter-transference'. This is the most dynamic way in which his patient's voice reaches him" (Heimann 1950: 82). Through acting out his conflicts in the relationship, by projection and pulling the analyst into acting out these unconscious dynamics, the patient displays his unconscious psychic structure. Therefore, Heimann argued that this makes countertransference "one of the most important tools for his work" as an "instrument of research into the patient's unconscious" (Heimann 1950: 81). Only when recognized and understood, countertransference experiences can be utilized as a tool and the analyst's participation in the patient's unconscious dramatization of his conflicts can be avoided.

These investigations into the close interaction between transference and countertransference and the reciprocity of introjection and projection (see Money-Kyrle 1956, Segal 1977) led to an understanding of countertransference as not only the feelings to- 
wards the patient but also those what he is made to feel like by the patient and what atmosphere consequently develops between patient and analyst. Following from this, the theoretical framework suggests that it cannot suffice to think about what is verbalized in analysis but rather on what is acted out in the relationship between patient and analyst, both in terms of transference and countertransference.

Later psychoanalytic theory then ventured out to describe and expand these unconscious interactions described by the concept of countertransference in greater detail (see Money-Kyrle 1956; Bion 1959). These contributions have made it possible to fully understand the mechanisms behind the relevance of countertransference as a therapeutic and diagnostic tool in psychotherapy. The processes of projection, introjection as means of unconscious communication could be understood as extremely early modes of communication that express verbally inexpressible emotions anxieties and fears.

Especially Bion formulated a clearer picture of how projective identification, the primary defence in the paranoid-schizoid position originally described by Klein $(1935,1946)$, structures interpsychic communication. The concept of projective identification describes how impulses together with split off parts of the ego are projected onto the object and in turn the object is internalized as transformed by the projective process. Excessive anxiety leads to excessive splitting and projecting and as a consequence a fragmentation of the ego takes place, arousing fears of annihilation and complete disintegration. As Klein describes, this is not only a method of expelling unbearable parts of the self but also a means of controlling the object (Klein 1946). Klein's distinction between the two positions was then further differentiated into levels of extremeness in the quality of their organisation (Bion 1957). Bion's contribution ties in both with Freud's two principles of mental functioning as well as Klein's ideas on projective identification. He investigated (1957) this phenomenon and differentiated between this pathological projective identification and a more productive communicative form that is healthy and necessary for normal development. Thereby, he conceptualized a more gradual transition from extreme paranoid schizoid functioning to various degrees of depressive functioning (Steiner 1992). Projective identification, he found, can not only be a defence of the paranoid-schizoid position but also serves as the initial means of communication between mother and child and constitutes the quality of the object relationship. The infant creates a connection to the mother by projecting its fears and aggression into her for her to experience and to perceive the inner state of the child. The mother, in return, is capable of transforming these projections in a state of "reverie", to mentalize the internal state of the infant, and thereby contain the anxieties of the baby. These modified psychic contents can be given back to the child and there create a more endurable experience, which fosters the capacity to think about its own state of mind and to internalize a good object (Bion 1962a; 1962b). This concept of the container-contained dyad of two minds where one helps the other one to develop a capacity to think and to tolerate difficult emotional states, is used to formulate a conception of the internal dynamics involved in mutual unconscious interaction.

In pathological projective identification, parts of the ego, which are concerned with reality, become fragmented and projected into the object, which in turn is perceived as a "bizarre object" which controls and encapsulates these projected parts of the self giving both the object and thoughts a concrete quality (Bion 1957).
Bion describes: "Each particle is felt to consist of a real object which is encapsulated in a piece of personality that has engulfed it. The nature of this complete particle will depend partly on the character of the real object [...] and partly on the character of the particle of personality that engulfs it" (1957: 268). This excessive fragmentation of the ego and the superego Bion describes the character of these objects as follows: "The patient now moves not in a world of dreams but in a world of objects, which are ordinarily the furniture of dreams" (Bion 1957). This process depletes and weakens the ego and bizarre objects contain super-ego and ego aspects of reality recognition that formerly belonged to the ego. Differentiating between conscious and unconscious, internal and external, self and object becomes impossible.

This minute description of processes between two minds made it possible to obtain a detailed understanding for the processes that Heimann (1950) and others have described in the transference - countertransference communication between patient and therapist and elaborate specifically on the function of countertransference as a therapeutic instrument. The concepts of the early communication between mother and infant directly relate to the relationship between therapist and patient. In the context of the therapy, Bion argued, it is the therapist's task to contain the negative disturbing projections by the patient and to stay calm despite these unconscious attacks. This mental capacity of the therapist, as a container, allows for a gradual transformation of these feelings and the capacity for both to obtain some knowledge of these early basic processes in the patient. With this communicative form of projective identification, therefore, the patient is able to put unthinkable thoughts into the mind of the analyst, where they can stay long enough to be modified in the psyche. Recognizing positive projective identification is of utmost importance to encourage and foster the patient's attempts to establish more meaningful relatedness to others and to build a trusting and authentic relationship (Hamilton 1986). Finally, it required Freud and his follower's long and meticulous research in psychoanalysis to develop an understanding of the mind that then allowed for the concepts discussed here to emerge. Only following these discoveries and with the dynamic psychoanalytic model in mind, it became possible to think in these complex terms about the interpersonal situation of the therapeutic setting.

Elsewhere (Parth, Hrusto-Lemes, Löffler-Stastka, in preparation), we argue for the centrality of countertransference in the context of treating traumatised patients. The understanding of trauma, especially when traumatising events cannot be remembered, is highly dependent of a correct perception, regulation and contextualisation of countertransference and transference dynamics in the therapeutic setting. As shown in our other paper, it requires exactly these aspects that are not verbally expressible to grasp what it is that the patients really feel and how his or her mind works. Trauma in the therapeutic relationship becomes expressed in the form of strong affects such as fear, anger, confusion, feelings of being powerless as well as guilt and shame, all feelings which correspond with the unbearable affects experienced in the traumatic event and are being relived in the relationship to the therapist. In the patient's mind, the traumatising effect is felt to be caused by the therapist (transference) or the therapist might be made to feel like a victim (projective identification). It is then the task of the therapist to make use of these dynamics, understand them, contain them and in consequence modify them so that they become bearable to the patient. In this manner it becomes possible to understand something about a traumatised mind even if the patient him or herself does not consciously remember. 
As trauma is something that overwhelms the mind, it causes processes of dissociation and splitting. Thereby, the mind is forced to regress to these early methods of dealing with aggression and psychic pressure mentioned above. Excessive projective processes become operative which in turn dictate the quality of the countertransference experience of the analyst. From the perspective of diagnostic concerns, these dynamics therefore become crucial indicators for possible traumatic experiences. The same applies to therapeutic measures in the course of the treatment. Research (Hrusto-Lemes 2010) has shown that the measurement of countertransference experiences in the context of assessment interviews clearly indicates a connection between different experiences of countertransference feelings of the interviewer and kinds of trauma experienced by different interviewed persons. Moreover, it has been shown from the empirical perspective that the influence and importance of countertransference can be observed qualitatively as well as quantitatively. Questionnaires such as the Therapist Response Questionnaire (CTQ) helps to display the correlation between the therapist's countertransference and the patient's specific personality pathologies (Betan, Heim, Zittel, Westen 2005).

Countertransference phenomena, as shown in psychoanalytic research and practice, cannot be avoided or prevented. In the contrary, they are part of every day interactions and become specifically strong in the encounter between patient and therapist, in the distilled relationship between these two agents. Regardless of the sort of therapy or process of diagnosis applied by the therapist, transference by the patient and countertransference on the end of the therapist will always be present. Utilized correctly and conceptualized by theories offered by psychoanalysis, these processes can be understood as early and intense forms of communication of the patient. Only then can a full understanding of internal world of the patient be achieved and crucial, verbally non-communica- ble processes, feelings and memories can be included in the treatment process and diagnosis.

\section{References}

[1]. Bion, W.R. 1957 Differentiation of the Psychotic from the Non-Psychotic Personalities. Int. J. Psycho-Anal., 38:266-275.

[2]. Bion, W.R. 1959 Attacks on Linking. Int. J. Psycho-Anal., 40:308- 315.

[3]. Bion, W.R. 1962a The Psycho-Analytic Study of Thinking. Int. J. PsychoAnal., 43:306-310.

[4]. Bion, W.R. 1962b Learning from Experience. London: Tavistock.

[5]. Colli, A. Tanzilli, G. Dimaggio, V. et al. 2013 Patient Personality and Therapist Response: An Empirical Investigation. American Journal of Psychiatry. AiA: $1-7$.

[6]. Dresser, I. (1985). Development of the Concepts of Transference and Countertransference. Psychoanal. Psychother., 1:13-23.

[7]. Hamilton, N.G. 1986 Positive Projective Identification. Int. J. PsychoAnal., 67:489-496.

[8]. Heimann, P. 1950 On Counter-Transference. Int. J. Psycho-Anal., 31:81-84.

[9]. Hrusto-Lemes, A (2010) Affektregulation, Objektbeziehungsqualität und Persönlichkeitsstörungen bei Traumatypen. Diplomarbeit an der Medizinischen Universität Wien ausgeführt an der Universitätsklinik für Psychoanalyse und Psychotherapie.

[10]. Kernberg, O.F. 1993 Convergences and Divergences in Contemporary Psychoanalytic Technique. Int. J. Psycho-Anal., 74: 659-67.

[11]. Klein, M 1935 A contribution to the psychogenesis of manic-depressive states. In: Klein, M. Love, Guilt and Reparation and Other Works 19211945. p. 262-290. London: Vintage

[12]. Klein, M 1946 Notes on some schizoid mechanisms. In: Klein, M.Envy And Gratitude And Other Works, 1946-1963. p. 1-25. London:Vintage

[13]. Money-Kyrle, R.E. 1956 Normal Counter-Transference and Some of its Deviations. Int. J. Psycho-Analysis, 37:360-366.

[14]. Parth, K. , Hrusto-Lemes A., Löffler-Stastka H. Authentic Clinical Care for Traumatized Patients. (in preparation)

[15]. Segal, H.M. 1977 Psychoanalytic Dialogue: Kleinian Theory Today. J. Amer. Psychoanal. Assn., 25:363-370

[16]. Steiner, J. 1992 The Equilibrium Between the Paranoid-Schizoid and the Depressive Positions. New Library of Psychoanalysis.

[17]. Weitzman, B. 1967 Behaviour Therapy and Psychotherapy. Psychological Review, 74:4, p. 300-317 